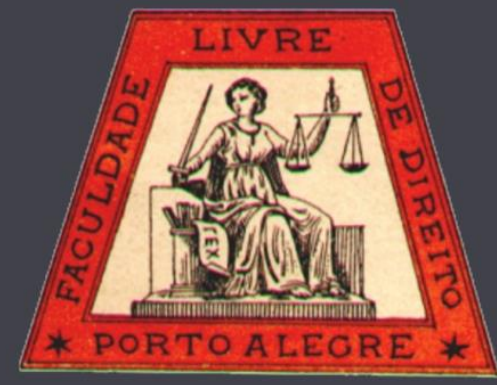

\title{
A violência simbólica no Poder Judiciário: desafios à efetividade da Lei Maria da Penha
}

The symbolic violence in the judicial power: challenges to the effectiveness of the Maria da Penha Act

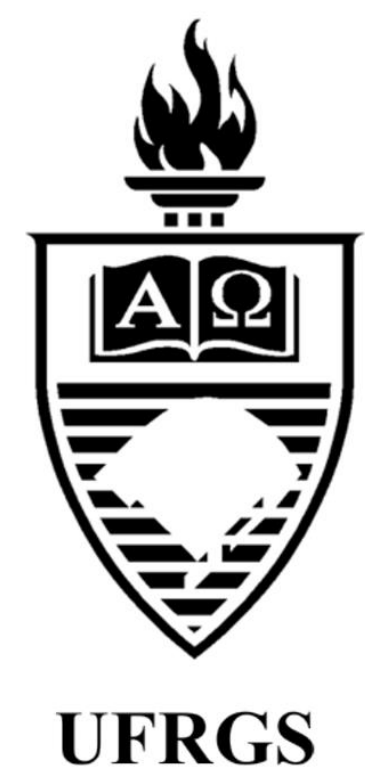

Artenira da Silva e Silva Sauaia Universidade Federal do Maranhão

Kennya Mesquita Passos

Faculdade do Maranhão 


\title{
A violência simbólica no Poder Judiciário: desafios à efetividade da Lei Maria da Penha
}

\author{
The symbolic violence in the judicial power: challenges to the effectiveness of the Maria da Penha \\ Act
}

Artenira da Silva e Silva Sauaia*

Kennya Regyna Mesquita Passos**

\section{REFERÊNCIA}

PASSOS, Kennya Regyna Mesquita; SAUAIA, Artenira da Silva e Silva. A violência simbólica no Poder Judiciário: desafios à efetividade da Lei Maria da Penha. Revista da Faculdade de Direito da UFRGS, Porto Alegre, n. 35, p. 137154, dez. 2016.

\section{RESUMO}

O objetivo deste trabalho é identificar, partindo de um estudo de caso, manifestações simbólicas patriarcais na aplicação da Lei Maria da Penha, e analisar, a partir da compreensão do magistrado a respeito das formas de violência contra a mulher e da condição de mulher em situação de violência, os desafios à efetividade na proteção aos Direitos Humanos das Mulheres, refletindo acerca da necessidade da capacitação técnica dos operadores do Direito nas temáticas de gênero, para o enfrentamento de todas as formas de violência contra a mulher, conforme disciplinam os estatutos jurídicos internacionais de proteção aos Direitos Humanos, e em especial a violência institucional, manifestada na violência simbólica, reproduzida pelo próprio Estado, que submete a mulher a uma dupla vitimização.

\section{PALAVRAS-CHAVE}

Violência simbólica. Lei Maria da Penha. Violência institucional.

\section{ABSTRACT}

The objective of this work is to identify, from a case study, symbolic manifestations of patriarchy in the application of the Maria da Penha Act, and to analyze, from the understanding of the magistrate about the forms of violence against women and womanhood in violence situation, the challenges to the effectiveness in protecting the human rights of women, reflecting on the need for technical training of legal professionals in gender thematic areas, in order to confront all forms of violence against women, according to the international legal instruments for the protection of human rights, particularly the institutional violence, manifested in symbolic violence, reproduced by the State itself, which submits the woman to a double victimization.

\section{KEYWORDS}

Symbolic violence. Maria da Penha Act. Institutional Violence.

\section{SUMÁRIO}

1. O gênero enquanto elemento constitutivo das relações entre os indivíduos. 2. Dominação e Violência Simbólica: a naturalização da desigualdade. 3. Tolerância social à violência contra a mulher: o patriarcado naturalizado. 4. Direitos Humanos das Mulheres: visibilizando violências. 5. Violência Institucional: um estudo de caso. 5.1 Da compreensão a respeito das formas de violência contra a mulher. 5.2 Da representação da mulher em situação de violência doméstica. 6. Reflexões necessárias. Conclusão. Referências.

\footnotetext{
* Professora da Universidade Federal do Maranhão - UFMA. Pós-doutora em Psicologia e Educação (Universidade do Porto, Portugal, 2014). Doutora em Saúde Coletiva (Universidade Federal da Bahia - UFBA, 2005). Mestre em Saúde e Ambiente (Universidade Federal do Maranhão - UFMA, 2000). Graduada em Psicologia (Pontifícia Universidade Católica de São Paulo - PUC-SP, 1990).

** Professora da Faculdade do Maranhão - FACAM. Mestranda em Direito e Instituições do Sistema de Justiça (Universidade Federal do Maranhão - UFMA). Especialista em Direito Público (Universidade Católica Dom Bosco, 2013). Graduada em Direito (Universidade Ceuma - UNICEUMA, 1999). Advogada.
} 
1 O GÊNERO ENQUANTO ELEMENTO CONSTITUTIVO DAS RELAÇÕES ENTRE OS INDIVÍDUOS

Antes de se tecer qualquer consideração sobre a violência contra a mulher ou sobre a efetividade da Lei Maria da Penha, necessário se faz compreender uma questão anterior e fundante do problema: o gênero enquanto elemento constitutivo das relações entre os indivíduos.

O gênero é uma construção cultural, social e linguística, que diferencia homens e mulheres para além das características biológicas, através de processos que produzem a definição seus corpos, seus lugares sociais, papéis e posições de poder (MEYER, 2005, p. 16).

Para Saffioti e Almeida, o gênero está relacionado a um processo no qual os indivíduos absorvem representações com significados próprios que os situam no mundo social:

[...] [O] componente do gênero é uma relação social, que remete os indivíduos a uma categoria previamente constituída. Coloca em relação um indivíduo com outros, determina se ele é pertencente a uma categoria e o posiciona face a outros pertencentes a outra categoria. (SAFFIOTI, 1995, p. 20)

Deste modo, para que se compreenda as posições que os indivíduos ocupam na sociedade, é necessário que ao lado das noções de classe e "raça"/etnia, seja utilizado o gênero como categoria de análise, a fim de permitir a compreensão do sentido e da natureza destes lugares sociais (SCOTT, 1990, p. 6).

Tendo-se o gênero como categoria de análise, logo se percebe que as relações entre os sexos se estabelecem sob uma determinada estrutura de poder, cujo objetivo é garantir o controle do comportamento, do corpo, da divisão sexual do trabalho, das funções reprodutivas e da sexualidade das mulheres. Eis as bases do "patriarcado", sistema que visa garantir a manutenção da dominação masculina e a hierarquia entre homens e mulheres (SAFFIOTI, 2004, p. 59), cuja origem se confunde com a história da própria humanidade, e que marca universalmente as relações de gênero, as formas de visão e divisão do mundo social, desde os tempos pré-históricos até os dias atuais:

\begin{abstract}
Una vez perfilado el contexto social en el que los sujetos han vivido, viven y vivirán no nos cabe duda alguna que este sistema de poder, el patriarcado construye la visión del mundo y de las realidades sociales. Además dirige, crea y marca los valores, las pautas, la moral, las conductas, las normas y la distribución del poder material, político y social de la sociedad. (MANSO; SAUAIA, não paginado)
\end{abstract}

Alessandro Baratta (1999, p. 45) destaca o importante papel do patriarcado na construção social dos gêneros, a partir do estabelecimento de diferentes regras de conduta e papéis a serem desempenhados por homens e mulheres:

\begin{abstract}
A estrutura dos papéis nas duas esferas da divisão social de trabalho, quais sejam, a da produção material e a da reprodução, não é menos importante. É nesta diferenciação das esferas e dos papéis na divisão do trabalho que age a construção social dos gêneros. A sociedade patriarcal reservou, de forma ampla, o protagonismo da esfera produtiva aos homens e do círculo reprodutivo, às mulheres.
\end{abstract}

$\mathrm{Na}$ divisão social e sexual do trabalho, a mulher foi remetida aos espaços privados da casa e da família e às atividades relacionadas à manutenção desses espaços, à função reprodutiva e aos cuidados com a prole, atribuições que são atravessadas pelas noções de docilidade, subordinação, fragilidade e inferioridade associadas às características da "natureza" feminina, enquanto o homem foi destinado aos espaços públicos de protagonismo, poder $\mathrm{e}$ decisão, associado por sua vez à figura de liderança, poder e força.

Constroem-se a partir daí os estereótipos como o da "boa mãe", da "esposa fiel”" e da "moça recatada", ao lado do "provedor do lar", do "homem de negócios", do "chefe de família", parâmetros que servirão de base para o exercício 
da "função patriarcal", que, segundo Saffioti, representa "[...] o poder de determinar a conduta das categorias sociais nomeadas, recebendo autorização, ou pelo menos tolerância da sociedade para punir o que lhes apresenta como desvio" (2001, p. 115).

Dito de outra forma, o exercício da função patriarcal pressupõe o poder de impor valores e regras de comportamento ao gênero feminino, e ao mesmo tempo, um direito "legítimo" de punir o comportamento tido como desviante em relação ao que foi culturalmente estabelecido para este gênero.

A insubordinação aos padrões impostos às mulheres pela ordem patriarcal é reprimida pela violência simbólica e punida pela violência física, sexual, psicológica e moral. Ou seja, o exercício da violência se constitui como um dos meios mais "eficazes" de controle do comportamento feminino na manutenção da ordem androcêntrica.

Nesta perspectiva, é possível afirmar que a violência contra a mulher é o ápice, a expressão máxima da desigualdade nas relações de gênero, manifestação da posição superior que deve ser ocupada pelo homem no mundo do trabalho, no ambiente doméstico e nas relações afetivas (SAFFIOTI, 1987).

Sendo assim, "corrigir', "conter" ou "punir" o comportamento da mulher através de insultos, xingamentos, ameaças e demais formas de agressões, são práticas quotidianas que por muito tempo passaram desapercebidas na dinâmica social, em razão da dominação masculina sobre todos os espaços sociais, e principalmente no espaço doméstico, onde por muito tempo acreditou-se ser um território de relações intocáveis pelo Estado.

Essas violências invisíveis que passaram a compor os debates públicos somente após muitos anos de lutas feministas, embora integrem atualmente uma consistente legislação protetiva dos direitos humanos das mulheres, encontra resistências em seu reconhecimento na vida prática em razão da reprodução da visão de mundo patriarcal, o que se dá inclusive no funcionamento do próprio Sistema de Justiça.

Apresentaremos neste artigo, de abordagem qualitativa, um estudo de caso com o qual, a partir da análise de conteúdo da sentença, buscaremos identificar manifestações simbólicas patriarcais na aplicação da Lei Maria da Penha, que embora não ofereça conclusões generalizáveis, traz ilustrativamente um modus de pensar específico, podendo suscitar reflexões acerca dos desafios à efetividade da proteção da mulher contra todas as formas de violência, inclusive aquelas perpetradas pelo próprio Estado.

\section{DOMINAÇÃO E VIOLÊNCIA SIMBÓLICA: A NATURALIZAÇÃO DA DESIGUALDADE}

A violência que decorre do exercício da "função patriarcal" possui uma dimensão simbólica uma vez que é fruto de um trabalho constante de produção e reprodução de ideologias e padrões próprios de uma categoria dominante, os quais precisam ser assimilados e naturalizados pelos dominados, manifestação de um "Poder Simbólico", caracterizado por Bourdieu como:

[...] [P]oder de construir o dado pela enunciação, de fazer ver e fazer crer, de confirmar ou de transformar a visão do mundo e, deste modo, a ação sobre o mundo, portanto o mundo; poder quase mágico que permite obter o equivalente daquilo que é obtido pela força (física ou econômica), graças ao efeito específico de mobilização, só se exerce se for reconhecido, quer dizer, ignorado como arbitrário. [...] Isto significa que o poder simbólico [...] se define numa relação determinada - e por meio desta - entre os que exercem o poder e os que lhe estão sujeitos, quer dizer, isto é, na própria estrutura do campo em que se produz e se reproduz a crença. (BOURDIEU, 2002, p. 14-15)

A "dominação simbólica" constitui na verdade uma forma de violência silenciosa e invisível - a "violência simbólica", que impõe aos dominados um "conformismo lógico" 
(BOURDIEU, 2002, p. 9) através da assimilação de valores, sistemas de comunicação, categorias, parâmetros de visão e divisão do mundo próprios dos dominantes:

A violência simbólica institui-se por meio da adesão que o dominado não pode deixar de conceder ao dominante (e, portanto, à dominação) quando ele não dispõe, para pensá-la e para se pensar, ou melhor, para pensar sua relação com ele, mais de que instrumentos de conhecimento que ambos têm em comum e que, não sendo mais que a forma incorporada da relação de dominação, fazem esta relação ser vista como natural; ou, em outros termos, quando os esquemas que ele põe em ação para se ver e se avaliar, ou para ver e avaliar os dominantes [...], resultam da incorporação de classificações, assim naturalizadas, de que seu ser social é produto. (BOURDIEU, 2003, p. 46)

É desta forma que o patriarcado se reproduz na sociedade, naturalizando a ordem androcêntrica, seus princípios, valores, relações de poder, papéis e funções destinadas aos indivíduos.

A dominação masculina, segundo Bourdieu (2003, p. 35), tem origem em uma construção arbitrária sobre os usos e funções dos corpos masculino e feminino, que vai justificar a divisão sexual do trabalho e, a partir dela, toda a estrutura social, de modo que a relação de dominação estará legitimada por uma natureza biológica - que é, ela própria, uma construção social naturalizada.

As construções arbitrárias de homens e mulheres constroem assim esquemas cognitivos com regras que impõe os comportamentos esperados e padrões de relacionamento entre os indivíduos, assimilados e naturalizados nas práticas sociais (SAFFIOTI, 2001, p. 118-119).

Nesse sentido, Bourdieu afirma que a ordem masculina não precisa de justificação porque se impõe como neutra através da dinâmica social, que reproduz e naturaliza o poder masculino:

A ordem social funciona como uma imensa máquina simbólica, tendendo a ratificar a dominação masculina na qual se funda: é a divisão social do trabalho, distribuição muito restrita das atividades atribuídas a cada um dos dois sexos, de seu lugar, seu momento, seus instrumentos. [...] (BOURDIEU, 2003, p. 15)

Desse modo, as categorias de identificação de masculino e feminino tornam-se os matizes dos pensamentos e percepções de todos os indivíduos na sociedade e, assim, a representação androcêntrica das diferenças biológicas e sociais entre homens e mulheres passa ao entendimento do senso comum e vai determinar as práticas sociais (BOURDIEU, 2003, p. 45).

\section{TOLERÂNCIA SOCIAL À VIOLÊNCIA CONTRA A MULHER: O PATRIARCADO NATURALIZADO}

Entre maio e junho de 2013, o IPEA, na $2^{\mathrm{a}}$ edição do Sistema de Indicadores de Percepção Social (SIPS), realizou uma pesquisa em 3.809 domicílios, distribuídos em 212 municípios de todas os Estados da federação, a fim de compreender a percepção dos brasileiros acerca de temas relacionados à violência contra a mulher. A pesquisa utilizou um método de amostragem probabilística com margem de erro de 5\%, a um nível de significância de 95\% para o Brasil e suas cinco macrorregiões.

A pesquisa, divulgada em abril de 2014, intitula-se "Tolerância social à violência contra a mulher" e aborda questões sobre o ordenamento patriarcal e heteronormativo da sociedade brasileira e sua relação com o fenômeno da violência contra a mulher. Apresenta dados que revelam na população uma adesão majoritária ao modelo patriarcal de família nuclear, embora numa versão "moderna", contemporânea, na qual o homem ainda é percebido como o chefe da família e a mulher com obrigação de "se dar ao respeito", numa relação em que as formas mais extremas de violência devem sofrer a intervenção do Estado, enquanto as "rusgas menores" devem 
permanecer apenas no espaço privado (IPEA, 2014, p. 3).

Segundo a pesquisa, embora a mulher tenha adentrado os espaços públicos, entre eles o mercado de trabalho, passando a ter economia própria, sendo bastante significativo o número de famílias chefiadas por mulheres, ainda é fortemente presente a figura do homem como aquele que detém a autoridade no ambiente doméstico, assim como os ideais estereotipados de realização feminina através do casamento e da maternidade.

Dos entrevistados e entrevistadas, 64\% concordam com a frase "o homem deve ser a cabeça do lar", $79 \%$ concordam que "toda mulher sonha em se casar", enquanto $60 \%$ concordam, que "uma mulher só se sente realizada quando tem filhos" (IPEA, 2014, p. 5-7).

No que diz respeito à sexualidade, às mulheres ainda se impõe um padrão de comportamento machista, que restringe sua liberdade, como se infere da afirmação: "tem mulher que é pra casar, tem mulher que é pra cama", admitida por $55 \%$ dos entrevistados (IPEA, 2014, p. 12).

De modo geral a pesquisa demonstra que permanecem as representações da mulher ligada à ideia de recato, cuidado da família e reprodução, que vão se traduzir em posturas nas relações de gênero e na percepção de violências, haja vista que, com exceção da violência física, repudiada por $91 \%$ dos entrevistados, outras formas de violência contra a mulher, como a violência psicológica, moral e econômica, são vistas como de menor importância ou gravidade, a ponto de ser desejável que as mesmas sejam resolvidas na esfera privada, considerando que $64 \%$ das pessoas acredita que "casos de violência dentro de casa devem ser discutidos somente entre os membros da família", quase $82 \%$ concordam que "em briga de marido e mulher, não se mete a colher" e $89 \%$ admitem que "roupa suja se lava em casa" (IPEA, 2014, p. 13-16).
Revela-se então que no ideário da sociedade brasileira nem todos os casos de violência contra a mulher devem chegar à esfera pública, existindo um limite aceitável de violência inerente às relações entre homens e mulheres no espaço doméstico. São violências invisibilizadas, comportamentos naturalizados e consequentemente sem relevância suficiente a ponto de receberem a tutela do Estado.

Pertencem a este grupo, mais comumente, as ofensas morais, os xingamentos e ameaças, quando, sob a égide dos valores patriarcais, se minimiza a responsabilidade do agressor justificando-se a violência em face do "calor da discussão", do uso de álcool, ou das "provocações" da vítima, esvaziando o caráter criminoso de comportamentos que violam direitos das mulheres, induzindo à tolerância, dando-lhes contornos de pouca ou nenhuma lesividade, naturalizados como parte integrante das relações de gêneros.

\section{DIREITOS HUMANOS DAS MULHERES: VISIBILIZANDO AS VIOLÊNCIAS}

Os movimentos feministas que emergiram a partir da década de 70 em defesa dos direitos humanos das mulheres, passaram a denunciar os abusos e violações às quais a sociedade patriarcal submete as mulheres, cobrando do Estado o reconhecimento e o combate à violência de gênero em todas as suas manifestações, e em especial, dando visibilidade às violências sofridas no âmbito doméstico e familiar.

Desde então, a violência contra a mulher passou a ser objeto de preocupação em diversos acordos e tratados internacionais, dos quais o Brasil é signatário, entre eles a "Convenção para a eliminação de todas as formas de discriminação contra a mulher", conhecida como a Lei Internacional dos Direitos da Mulher, de 1979, a "Declaração de Eliminação da Violência contra a Mulher" de 1993, a "Plataforma de Ação de 
Beijing da Quarta Conferência Mundial da Mulher", realizada em 1998, e o "Protocolo de Palermo" de 2004.

Merecem destaque ainda outros documentos como a "Conferência Mundial sobre os Direitos Humanos", realizada pela Organização das Nações Unidas (ONU), em 1993, na Áustria, que reconheceu as mulheres como sujeitos internacionais de direitos, a existência da violência de gênero e a necessidade de seu enfrentamento nas esferas pública e privada, bem como o combate à violência institucional, sobretudo na administração da justiça, como dever prioritário dos Estados:

Art. 18. A violência com base no gênero da pessoa e todas as formas de assédio e exploração sexual, incluindo as resultantes de preconceitos culturais e tráfico internacional, são incompatíveis com a dignidade e o valor da pessoa humana e devem ser eliminadas. [...]

Art. 36. A Conferência Mundial sobre os Direitos Humanos apela para que o pleno gozo, pelas mulheres, de todos os direitos humanos, em condições de igualdade, seja definido como uma prioridade dos Governos e das Nações Unidas. [...] Art. 38. A Conferência Mundial sobre os Direitos Humanos salienta, em particular, a importância de se trabalhar no sentido da eliminação da violência contra as mulheres na vida pública e privada, da eliminação de todas as formas de abuso sexual, da exploração e do tráfico de mulheres, a eliminação de preconceitos discriminatórios na administração da justiça. [...] (ORGANIZAÇÃO DAS NAÇÕES UNIDAS, 1993, não paginado)

\section{A "Convenção Interamericana para}

Prevenir, Punir e Erradicar a Violência contra a Mulher", conhecida como "Convenção de Belém do Pará", realizada em 1994, resultado de aproximadamente duas décadas de movimentos organizados em defesa dos direitos das mulheres no Brasil, traz um importante conceito de violência contra a mulher e impõe deveres aos Estados:

Art. $1^{\circ}$ : Para os efeitos desta Convenção, entenderse-á por violência contra a mulher qualquer ato ou conduta baseada no gênero, que cause morte, dano ou sofrimento físico, sexual ou psicológico à mulher, tanto na esfera pública como na esfera privada. [...] Art. $7^{\circ}$ : Os Estados Partes condenam todas as formas de violência contra a mulher e convêm em adotar, por todos os meios apropriados e sem demora, políticas destinadas a prevenir, punir e erradicar tal violência e a empenhar-se em:

a. abster-se de qualquer ato ou prática de violência contra a mulher e velar por que as autoridades, seus funcionários e pessoal, bem como agentes e instituições públicos ajam de conformidade com essa obrigação;

b. agir com o devido zelo para prevenir, investigar e punir a violência contra a mulher;

c. incorporar na sua legislação interna normas penais, civis, administrativas e de outra natureza, que sejam necessárias para prevenir, punir e erradicar a violência contra a mulher, bem como adotar as medidas administrativas adequadas que forem aplicáveis;

d. adotar medidas jurídicas que exijam do agressor que se abstenha de perseguir, intimidar e ameaçar a mulher ou de fazer uso de qualquer método que danifique ou ponha em perigo sua vida ou integridade ou danifique sua propriedade;

e. tomar todas as medidas adequadas, inclusive legislativas, para modificar ou abolir leis e regulamentos vigentes ou modificar práticas jurídicas ou consuetudinárias que respaldem a persistência e a tolerância da violência contra a mulher;

f. estabelecer procedimentos jurídicos justos e eficazes para a mulher sujeitada a violência, inclusive, entre outros, medidas de proteção, juízo oportuno e efetivo acesso a tais processos;

g. estabelecer mecanismos judiciais e administrativos necessários para assegurar que a mulher sujeitada a violência tenha efetivo acesso a restituição, reparação do dano e outros meios de compensação justos e eficazes;

h. adotar as medidas legislativas ou de outra natureza necessárias à vigência desta Convenção. (ORGANIZAÇÃO DOS ESTADOS AMERICANOS, 1994, não paginado, grifo nosso)

No entanto, somente em 2006 o Brasil inaugurou em seu ordenamento legislação específica a respeito do tema, anos após ter sido condenado pela Organização dos Estados Americanos (OEA) por violação da respectiva convenção, negligência e omissão em relação à violência doméstica, no caso de Maria de Penha Fernandes, vítima de tentativa de homicídio pelo marido e revitimizada pelo Sistema Penal 
brasileiro, que demorou quase 20 anos para levar $\mathrm{o}$ autor a júri popular.

A Lei Maria da Penha, como é conhecida a Lei 11.340/2006, surge como um esforço para prevenir e punir a violência doméstica e familiar, criando mecanismos de proteção às mulheres em situação de violência, além de trâmites processuais mais adequados ao processamento dos casos, a partir da compreensão de que nenhuma forma de violência praticada no âmbito das relações privadas pode ser considerada de pouca relevância ou lesividade, dando visibilidade às relações de desigualdade de gênero e violência simbólica, que embora subjugassem centenas de mulheres diariamente, permaneciam despercebidas ou toleradas pela sociedade patriarcal.

Neste intuito, a Lei Maria da Penha, em seu art. 41, afastou expressamente a incidência da Lei 9.099/95, Lei dos Juizados Especiais, sua lógica conciliatória e dispositivos despenalizadores ${ }^{1}$, criando um sistema próprio, criminalizador, de modo a afirmar que os crimes envolvendo violência doméstica e familiar contra a mulher têm relevante potencialidade ofensiva.

Da mesma forma, o referenciado diploma revela as diversas formas de violência contra a mulher, destacando "pedagogicamente" a violência física, psicológica, sexual, patrimonial e moral:

Art. $7^{\circ}$ : São formas de violência doméstica e familiar contra a mulher, entre outras:

I - a violência física, entendida como qualquer conduta que ofenda sua integridade ou saúde corporal;

II- a violência psicológica, entendida como qualquer conduta que lhe cause dano emocional e diminuição da autoestima ou que lhe prejudique e perturbe o pleno desenvolvimento ou que vise degradar ou controlar suas ações, comportamentos, crenças e decisões, mediante ameaça, constrangimento, humilhação, manipulação, isolamento, vigilância

\footnotetext{
${ }^{1}$ As medidas despenalizadoras afastam a punibilidade do acusado e são aplicadas de modo geral nos crimes considerados de menor potencial ofensivo (cuja pena máxima é ultrapassa 2 anos): composição civil (reparação
}

constante, perseguição contumaz, insulto, chantagem, ridicularização, exploração e limitação do direito de ir e vir ou qualquer outro meio que lhe cause prejuízo à saúde psicológica e à autodeterminação;

III - a violência sexual, entendida como qualquer conduta que a constranja a presenciar, a manter ou a participar de relação sexual não desejada, mediante intimidação, ameaça coação ou uso da força; que a induza a comercializar ou a utilizar, de qualquer modo, a sua sexualidade, que a impeça de usar qualquer método contraceptivo ou que a force ao matrimônio, à gravidez, ao aborto ou à prostituição, mediante coação, chantagem, suborno ou manipulação; ou que limite ou anule o exercício de seus direitos sexuais e reprodutivos;

IV - a violência patrimonial, entendida como qualquer conduta que configure retenção, subtração, destruição parcial ou total de seus objetos, instrumentos de trabalho, documentos pessoais, bens, valores e direitos ou recursos econômicos, incluindo os destinados a satisfazer suas necessidades;

$\mathrm{V}$ - a violência moral, entendida como qualquer conduta que configure calúnia, difamação ou injúria. (BRASIL, 2006, não paginado)

Tais disposições refletem um avanço das conquistas feministas (MACHADO, 2013, p. 84) no sentido de combater a invisibilidade dos diversos tipos violência a que são submetidas as mulheres, impondo forçosamente a atuação do Estado no ambiente privado, a fim de coibir as relações de dominação-exploração nas relações íntimas, evidenciando um dos principais lemas do feminismo: "o pessoal é político" (MANSO; SAUAIA, 2015).

Outro ponto que merece destaque é a imposição às autoridades públicas, sobretudo àquelas incumbidas diretamente da aplicação da lei, do dever de abster-se de quaisquer atos que impliquem em violência contra a mulher, incluindo-se aqui, a violência simbólica, verificada na produção e reprodução de uma visão de mundo androcênctrica.

de dano), transação penal, suspensão condicional do processo e, exigência de representação para a lesão leve e culposa. 
No entanto, a entrada em vigor de uma norma jurídica, por si só, não tem o condão de mudar a realidade social, fazendo-se indispensável a atuação dos agentes estatais na interpretação e aplicação da lei, afim de assegurar a vontade do legislador, combatendo as manifestações da desigualdade de gênero e todas as formas de violência contra a mulher.

Por esta razão o art. $8^{\circ}$ da Lei 11.340/2006 determina que as políticas públicas de combate à violência doméstica e familiar contra a mulher terão como diretriz a capacitação permanente dos profissionais do Poder Judiciário, entre outros, a fim de fornecer o instrumental necessário para o tratamento adequado das questões de gênero.

Apresenta-se aqui um dos maiores desafios à afetividade da Lei 11.340/2006, uma vez que os operadores da norma estão inseridos no mesmo campo social em que o patriarcado se manifesta cotidianamente, sujeitos à assimilação dos parâmetros androcêntricos e à sua consequente reprodução na prática jurisdicional.

Uma tal ruptura só pode se dar pela necessária qualificação técnica daqueles que operam o referido dispositivo legal. Uma formação técnica específica deve garantir aos operadores do direito a compreensão das relações de desigualdade de gênero e das estruturas simbólicas patriarcais na sociedade brasileira. Do contrário, não será possível vislumbrar que a Lei Maria da Penha seja efetivada na proteção da mulher brasileira vítima de violência doméstica. Sua aplicação não qualificada tende a contribuir na perpetuação da violência simbólica masculina na forma de violência institucional.

\section{VIOLÊNCIA INSTITUCIONAL: UM ESTUDO DE CASO}

A má compreensão da natureza das relações gênero e a decisão judicial baseada no patriarcado "naturalizado" ferem de morte toda a legislação de proteção aos direitos humanos das mulheres, e resulta na antítese de seus objetivos, pois através da neutralidade e universalidade próprias da linguagem jurídica, é invisibilizada a violências contra a mulher, ratificando no mundo social as práticas machistas e a tolerância à violação de seus direitos, constituindo a sentença um verdadeiro "ato simbólico de nomeação", como ensina Bourdieu (2002, p. 273):

\begin{abstract}
O veredicto do juiz, que resolve os conflitos ou as negociações a respeito de coisas ou de pessoas ao proclamar publicamente o que elas são na verdade, em última instancia, pertence à classe dos actos de nomeação ou de instituição, diferindo assim do insulto lançado por um simples particular [...] que só compromete o seu autor, não tem qualquer eficácia simbólica; ele representa a forma por excelência da palavra autorizada, palavra pública, oficial, enunciada em nome de todos perante todos: estes enunciados performativos, enquanto juízos de atribuição formulados publicamente por agentes que atuam como mandatários autorizados de uma coletividade [...] são atos mágicos que são bem sucedidos porque estão à altura de se fazerem reconhecer universalmente, portanto de conseguir que ninguém possa recusar ou ignorar o ponto de vista, a visão, que eles impõem.
\end{abstract}

Segundo o autor, os atos simbólicos de nomeação constroem o mundo social a partir de esquemas de percepção e apreciação historicamente construídos, elevando a doxa a um grau de existência superior, o da "instituição instituída" (BOURDIEU, 2002, p. 238).

Desta forma, um dos efeitos simbólicos do veredito judicial pode ser a consagração da ordem estabelecida, que no caso das relações de gênero, é a doxa masculina, androcênctrica, heteronormativa, patriarcal, num processo de legitimação da estrutura da qual é resultado.

O estudo de caso que abordaremos agora se propõe a identificar a lógica patriarcal na aplicação da Lei Maria da Penha, demonstrando a dificuldade do acesso à Justiça quando o Estadojuiz invisibiliza a violência e demarca o comportamento esperado da vítima a partir do lugar social que o patriarcado estabelece para as mulheres. 
Trata-se de ação penal que tramitou na Vara Especial de Violência Doméstica e Familiar contra a Mulher da Comarca de São Luís - MA, tendo havido o oferecimento de denúncia em junho de 2015 pelo crime de ameaça, tipificado no art. 147, caput c/c art. 61, inciso II, alínea "f" do Código Penal c/c art. $5^{\circ}$, III e art. $7^{\circ}$, II da lei $11.340 / 2006 .^{2}$

Consta do Relatório Policial que a vítima fora agredida verbalmente e ameaçada de morte pelo ex-marido, por ter se recusando a entregar a filha menor, que se negava a ir com o pai, tendo a própria criança pedido ajuda por telefone a uma terceira pessoa.

$\mathrm{O}$ inquérito foi instruído com documentação hábil a demonstrar um quotidiano de violência moral e psicológica no relacionamento dos ex-cônjuges, onde se verificam diversas acusações e ofensas proferidos pelo acusado à vítima, relatórios técnicos apresentados por esta, bem como os depoimentos de testemunhas que presenciaram o fato e seu desenrolar, e as oitivas do acusado, da menor e da vítima.

De acordo com a denúncia, "a materialidade do delito é inconteste diante do Boletim de Ocorrências, enquanto a autoria encontra-se demonstrada pelo depoimento da vítima, que é firme e conciso em apontar o denunciado como autor do delito [...] bem como pelas testemunhas às fls. $[\ldots]$ ".."

No entanto, a decisão de mérito proferida pelo magistrado, quatro meses após o recebimento da exordial, dispensou a instrução do feito e absolveu sumariamente o réu, com

\footnotetext{
2 Ameaçar alguém, por palavra, escrito ou gesto, ou qualquer outro meio simbólico, de causar-lhe mal injusto e grave, com agravante genérica de o agente ter cometido o crime com violência contra mulher no âmbito de relações domésticas em razão de anterior coabitação, na forma de violência psicológica, entendida como qualquer conduta que lhe cause dano emocional e diminuição da autoestima ou que lhe prejudique e perturbe o pleno desenvolvimento ou que vise degradar ou controlar suas ações,
}

base nos arts. 397, III e 415, III, do Código de Processo Penal ${ }^{3}$, sentença na qual se lê:

[...] [I]ncumbe verificar se os autos fornecem elementos necessários e suficientes à comprovação da autoria e materialidade do delito imputado na denúncia. Para tanto, imprescindível o exame das provas tanto na fase inquisitorial quanto em Juízo para o crime tipificado na denúncia. $\mathrm{Na}$ apuração da ameaça dirigida pelo denunciado à vítima, a prova contida nos autos, a meu sentir, não é firme para sustentar um decreto condenatório, haja vista que para que se configure o crime previsto no artigo 147 do Código Penal, a ameaça deve ser idónea, séria, concreta, capaz de incutir medo à vítima.

O bem jurídico tutelado aqui é a liberdade pessoal e individual de autodeterminação, assim, a promessa de mau futuro deve revelar na vítima grande temor e insegurança, afetando sua liberdade psíquica e tolhendo sua liberdade de movimentação, e, o que se verifica nos autos é que, ao momento do fato, havia uma grande discussão entre as partes com semelhante nível de animosidade. [...]

Assim, entendo que a conduta praticada pelo acusado não se subsume ao tipo descrito no art. 147 do Código Penal, pois não houve intimidação suficiente da vítima, a ponto de causar-lhe justo receio de sofrer mal injusto e grave, haja vista se tratar tão somente de uma discussão de ânimos exaltados. Entendo, desse modo, que o conjunto probatório não aponta a ocorrência da conduta antijurídica, porquanto a configuração da ameaça requer a intenção fria e refletida de pronunciar um mal a alguém. [...]

O conteúdo presente nos trechos da sentença transcritos acima, permite identificar claras manifestações da cultura patriarcal e fazer inferências acerca da compreensão do magistrado sobre violência contra a mulher e sobre a mulher em situação de violência.

Inicialmente cabe esclarecer que, embora o exame das provas tanto na fase inquisitorial quanto em juízo tenha sido reconhecido como

comportamentos, crenças e decisões, mediante ameaça, constrangimento, humilhação, manipulação, isolamento, vigilância constante, perseguição contumaz, insulto, chantagem, ridicularização, exploração e limitação do direito de ir e vir ou qualquer outro meio que lhe cause prejuízo à saúde psicológica e à autodeterminação.

3 “Após a resposta do acusado, o juiz deverá absolver sumariamente o acusado quando verificar que o fato narrado evidentemente não constitui crime." 
"imprescindivel" no texto da aludida decisão, para a comprovação da existência de materialidade e autoria, há uma contradição entre este entendimento e o embasamento da sentença absolutória, uma vez que a Ação Penal não foi instruída, isto é, não houve a produção de provas em juízo, sob o crivo do contraditório, de modo que as partes não puderam ser ouvidas na presença do juiz, não puderam fazer perguntas às testemunhas, não puderam solicitar provas periciais ou o acompanhamento de equipe multidisciplinar, que entre outras atribuições, de acordo com o art. 30 da Lei 11.340/2006, pode fornecer subsídios por escrito ao juiz, ao Ministério Público e à Defensoria Pública, mediante laudos ou verbalmente em audiência.

Desse modo, prescindindo das provas colhidas em juízo, o que fundamentou a sentença? A decisão pautou-se no entendimento de que "uma discussão de ânimos exaltados", entre homem e mulher, no contexto de relações domésticas e familiares, não é capaz de gerar "intimidação suficiente da vítima, a ponto de causar-lhe justo receio de sofrer mal injusto $e$ grave", logo, não há conduta típica, antijurídica e culpável.

Para melhor apresentar os resultados da análise de conteúdo, dividiremos a discussão em duas categorias temáticas a seguir: "Da compreensão a respeito das formas de violência contra a mulher" e "Da representação da mulher em situação de violência doméstica".

\subsection{Da compreensão a respeito das formas de violência contra a mulher}

Buscaremos nesta categoria, inferir e interpretar a forma como a violência doméstica é compreendida/significada pelo juiz no caso em análise.

Ao absolver sumariamente o réu, portanto sem provas periciais que pudessem aferir os reflexos do comportamento do acusado na saúde psicológica e física da vítima, a sentença nega completamente a violência psicológica enquanto modalidade de violência contra a mulher nas relações domésticas e familiares.

Ressalte-se aqui, que as modalidades de violência moral e psicológica, foram expressamente trazidas pela Lei Maria da Penha. Essa opção do legislador objetiva dar visibilidade a um tipo de violência, que ao contrário da violência física, não deixa marcas visíveis na vítima, dispondo o juiz de uma equipe técnica multidisciplinar para orientá-lo quando da verificação destes casos.

A fim de elidir o crime de ameaça, a sentença não faz qualquer distinção entre uma conduta praticada em situação de violência doméstica contra a mulher e uma conduta proferida fora desse contexto, ignorando as especificidades das relações de desigualdade de gênero e aplicando ao caso, o entendimento da doutrina "tradicional" que exige um "ânimo calmo e refletido" por parte do autor para a tipificação do crime de ameaça.

No entanto esta exigência doutrinária e jurisprudencial é anterior à lei 11.340/2006 e consequentemente não poderia ser aplicada da mesma forma no âmbito das relações tuteladas pela Lei Maria da Penha, pois como ensina Maria Berenice Dias (p.47), embora não se verifiquem alterações dos tipos penais, houve inegável ampliação de seu âmbito de abrangência, haja vista que o texto legal, em seu art. $7^{\circ}$, inciso II, incrimina "qualquer conduta" contra a mulher que:

[...] [L]he cause dano emocional e diminuição da autoestima ou que lhe prejudique e perturbe o pleno desenvolvimento ou que vise degradar ou controlar suas ações, comportamentos, crenças e decisões, mediante ameaça, constrangimento, humilhação, manipulação, isolamento, vigilância constante, perseguição contumaz, insulto, chantagem, ridicularização, exploração e limitação do direito de ir e vir ou qualquer outro meio que lhe cause prejuízo à saúde psicológica e à autodeterminação. (BRASIL, 2006, não paginado) 
Novamente a opção do legislador visa dar visibilidade à violência moral e psicológica, afastando as justificativas que "naturalizam" as agressões sofridas pelas mulheres.

No entanto, no caso em estudo, o ato do agressor é facilmente "justificado" em razão de seu estado anímico, a fim de desqualificar a agressão como merecedora de uma providência estatal. São justificadas assim todas as injúrias, intimidações e demais agressões que não passam ao plano da violência física.

Descaracterizar as formas cotidianas de violência, que em geral não apenas antecedem, mas acompanham as demais, equivale a defender que as mulheres devem aceitar a condição de humilhação a elas imposta, obrigando-as, de forma sutil, à aceitação de uma condição de submissão, que todo uma legislação reconhece como violação de direitos humanos.

Observe-se ainda, que o estado anímico do autor, embora seja o "gatilho" da violência, não é a sua causa primeira, pois esta repousa antes no poder legitimado de agir, na crença naturalizada de que o homem está autorizado a subordinar, corrigir, controlar as mulheres, impor-lhes a sua vontade. E assim, quando grita para que ela o obedeça, não o faz somente por estar enraivecido, mas por acreditar que pode fazê-lo, tornando-se a “exaltação de ânimo" um álibi eficiente.

Da mesma forma, ao minimizar a potencialidade lesiva do comportamento do acusado em uma "discussão de ânimos exaltados”, a sentença demonstra novamente o desconhecimento das especificidades que envolvem a violência de gênero conta a mulher, vítima preferencial das rotinizadas agressões familiares e domésticas (SAFFIOTI; ALMEIDA, 1995, p. 36).

Sobre o tema, a literatura especializada aponta três fases distintas de ciclos de violência doméstica, que podem se alternar indefinidamente, com apresentação de comportamentos de violência de grau variável. Há um primeiro momento de agressões verbais que podem ocasionalmente chegar às vias de fato, uma segunda fase caracterizada por uma descarga de tensão incontrolável, que pode culminar em agressões mais graves, e uma terceira fase que corresponde a um período pacífico de reconciliação temporária (AGUIAR, 2002).

Deste modo, é inegável que durante uma acalorada discussão, no âmbito das relações domésticas e familiares, ao contrário do que ocorre em outros contextos, podem ser cometidos diversos delitos, sobretudo havendo violências psicológicas e morais manifestadas comumente na forma de ameaças e injúrias (MACHADO, 2013, p. 88), com o poder de lesar a saúde física e psicológica das vítimas.

Aliás, no intuito de demonstrar a potencialidade lesiva de condutas desta natureza é que a Lei Maria da Penha proíbe que lhes seja dispensado o mesmo tratamento que os crimes de menor potencial ofensivo.

No entanto, a decisão judicial inverte a lógica protetiva e traz para o campo jurídico o entendimento da doxa patriarcal que consiste em "tolerar" a violência contra a mulher, desde que em um certo "limite", isto é, valorizando as agressões físicas em detrimento de agressões morais e psicológicas, consideradas pelo julgador como menos importantes, devendo por isto permanecer longe do alcance do Estado, pelo menos enquanto a violência não passe ao plano físico.

Verifica-se que a não intervenção estatal, nem mesmo para permitir às partes a produção de provas, tem o efeito contrário daquele desejado pela Lei Maria da Penha, pela Constituição Federal e por toda a legislação internacional de proteção aos Direitos Humanos das Mulheres, fechando as portas do Judiciário em face da equivocada compreensão acerca do que seja a violência contra a mulher e seu contexto, bem como dos parâmetros de visão e divisão das 
relações de gênero, o que pode contribuir para a ineficácia da proteção e para o aumento dos números de violência contra a mulher.

\subsection{Da representação da mulher em situação de violência doméstica}

Nesta categoria nos propomos a identificar a forma como a decisão judicial compreende e significa a mulher enquanto sujeito que vivencia uma situação de violência.

Verifica-se que a despeito de ter procurado o Judiciário por sentir-se ameaçada, e assim o declarar, a condição de vítima foi afastada na sentença, porque em seu comportamento, a mulher não demonstrou "grande temor $e$ insegurança, afetando sua liberdade psíquica e tolhendo sua liberdade de movimentação".

Ocorre, como já dito anteriormente, que os danos causados pela violência psicológica se manifestam na saúde psicológica da vítima, de modo que o seu grau de temor ou afetação diante da conduta do acusado deveria ser analisado pelo juiz a partir de seu depoimento pessoal e de laudos periciais, o que foi impossibilitado no caso em estudo, pela absolvição sumária, que dispensou a instrução processual.

Ressalte-se aqui, a título de parênteses, que tal decisão ignorou solenemente a existência de diversos precedentes do Superior Tribunal de Justiça e do Supremo Tribunal Federal ${ }^{4}$, que entendem que nos crimes de ameaça ocorridos no ambiente doméstico a palavra da vítima assume valor probatório de maior robustez, suficiente para lastrear a persecução penal, reconhecendo as Egrégias Cortes que delitos desta natureza geralmente são perpetrados à margem de testemunhas.

No entanto, a percepção de que a mulher não se sentiu ameaçada recai sobre o fato de que ela participava da discussão em "semelhante nível de animosidade", o que revela que a representação de uma mulher em situação de violência ainda se encontra fortemente marcada pelas características de "fragilidade" e "passividade" atribuídas ao comportamento feminino pela sociedade patriarcal.

A vítima que chora, que se deixa subjugar, é mais facilmente reconhecida como vulnerável do que aquela que se afasta desses padrões, assumindo uma postura ativa ao enfrentar o agressor.

Demonstra-se assim que o Estado-juiz tem dificuldade em reconhecer a condição de vulnerabilidade da mulher decorrente da própria natureza das relações de gênero numa sociedade androcêntrica, utilizando em seu lugar os estereótipos produzidos pelas relações patriarcais para aferir a sua condição de vítima de violência doméstica.

Diante dos papéis cristalizados de gênero, a palavra da vítima e o sentimento de ameaça que a faz socorrer-se no Judiciário, não servem para demonstrar a existência do crime, nem mesmo como indício, a fim de autorizar a instrução penal.

Desse modo o acesso à Justiça deixa de ser um direito e passa a ser uma "oportunidade", conferida apenas àquelas que se amoldam às "identidades" construídas pela ordem patriarcal.

\section{REFLEXÕES NECESSÁRIAS}

O posicionamento manifestado pela Vara especializada em violência doméstica e familiar contra a mulher, no caso em estudo, demonstra o quanto é incipiente a habilitação técnica para a compreensão e percepção das diversas formas de violência às quais são submetidas as mulheres, sobretudo a violência psicológica, na qual uma das vias mais comuns de manifestação são as agressões verbais que ocorrem entre cônjuges, parceiros e ex-parceiros no âmbito das relações 
privadas, território no qual as leis anteriores não permitiam o acesso do Estado, mas que pode e deve ser desbravado pela Lei Maria da Penha.

Além da inefetividade na perspectiva repressiva e punitiva da política criminal lançada pela Lei Maria da Penha, a sentença analisada, enquanto "ato simbólico de nomeação", ao absolver sumariamente o acusado em um crime dessa natureza, sem sequer demonstrar minimamente a necessidade de instrução probatória, tem como efeito simbólico a banalização das violências psicológica e moral, das condutas de homens que ofendem, humilham, ridicularizam e ameaçam mulheres, não porque estejam com os ânimos exaltados, mas antes, porque estão autorizados a fazê-lo, sem que isto seja considerado um crime, pois como observa ARENDT (2009, p. 68), a violência é sempre "justificada" por uma causa maior, a legitimidade do poder para exercê-la.

A violência contra a mulher é um fenômeno complexo, e segue uma linha crescente que tem início, quase sempre, com "discussões de ânimos exaltados" e chega ao fim, muitas vezes, com o silêncio sepulcral da mulher.

Nesse sentido é o relatório do Núcleo de Estudos sobre o Crime e a Pena da Escola de Direito da Fundação Getúlio Vargas, na pesquisa "A violência doméstica fatal: o problema do feminicídio íntimo no Brasil”, onde se lê que:

[...] [A] violência fatal é o desfecho em alguma medida previsível de relacionamentos em que são comuns xingamentos, ameaças, agressões. É bastante presente, na análise dos feminicídios íntimos, o histórico de violência doméstica na relação entre vítimas e autores. Esse convívio violento por muitas vezes mostrou-se naturalizado tanto pela mulher quanto pelo homem ou por testemunhas envolvidas. (FGV, 2015, grifo nosso)

A pesquisa "Violência contra a mulher: feminicídios no Brasil" realizada pelo IPEA no período entre 2009 e 2011, constatou que não houve impacto nas taxas anuais de mortalidade de mulheres por feminicídio (mortes decorrentes de conflitos de gênero) após a entrada em vigor da Lei 11.340/2006, salvo no ano de 2007, com o imediato retorno aos índices anteriores.

Associadas ao estudo de caso trazido em nossa pesquisa, estas informações nos levam a refletir sobre o perigo de banalizar e invisibilizar a violência moral e psicológica contra a mulher.

Quando o Judiciário tolera ameaças e intimidações no contexto doméstico, considerando-os fatos irrelevantes, minimiza agressões em discussões exaltadas como "inofensivas", aceitando-as como inerentes às relações entre homens e mulheres, além de duplicar a vitimização da mulher pela violência institucional que representa, a sociedade recebe como resultado prático, um verdadeiro mandado autorizador para que crimes mais graves sejam praticados.

Quebrar esse ciclo de violência é dever prioritário do Estado, que precisa dar respostas penais fortes e efetivas às primeiras manifestações de violência doméstica, a fim de conter o progresso dessa marcha.

No entanto é necessário primeiro compreender as especificidades da violência contra a mulher enquanto manifestação das relações de desigualdade de gênero, separando estes crimes das outras situações de violência, a fim de garantir a adequada aplicação do sistema legal.

A incompreensão destas questões e a reprodução dos parâmetros e valores patriarcais pelo próprio Judiciário, leva à má aplicação da lei e pode levar também à morte de seres humanos, unicamente por sustentarem a condição de ser mulher.

\section{CONCLUSÃO}

A sociedade brasileira permanece fortemente marcada pela cultura patriarcal que historicamente manteve a mulher em uma posição 
de inferioridade e submissão nas relações de gênero.

O patriarcado se perpetua num ciclo de dominação simbólica através de valores, padrões de comportamento, sistemas de comunicação, assimilados e reproduzidos cotidianamente.

A luta dos movimentos feministas para dar visibilidade à situação de dominação-exploração das mulheres nas relações de gênero e às várias formas de violência sofridas, principalmente na esfera doméstica, fez surgir internacionalmente o reconhecimento dos direitos humanos das mulheres, e a necessidade de combater todas as formas de violência contra a mulher, inclusive as praticadas pelo próprio Estado.

No Brasil, a Lei Maria da Penha inaugurou no ordenamento jurídico um sistema de proteção à mulher em situação de violência doméstica e familiar, visando garantir a atuação do Estado na esfera das relações privadas, até então desprotegida e subvalorizada.

Objetivando punir a violação a direitos e coibir a prática de crimes, a Lei 11.340/2006 reconheceu expressamente várias formas de violência contra a mulher, entre elas as violências psicológica e moral, invisibilizadas até então, prevendo permanente capacitação nas questões de gênero para os seus agentes, a fim de permitir a identificação e a consequente criminalização de todas as formas de violência contra a mulher.

No entanto, pôde-se observar, no estudo de caso apresentado, que os valores e princípios patriarcais são trazidos ao campo jurídico, afetando a compreensão e a identificação das formas de violência contra a mulher e a situação de vulnerabilidade da mulher vítima de violência doméstica.

A inadequação da vítima aos padrões de gênero estabelecidos pelo patriarcado e a justificação do comportamento do agressor em face de seu estado anímico afastam a caracterização do crime sem qualquer exame de provas produzidas em juízo, como se os fatos narrados na denúncia tratassem de uma relação comum entre pessoas na mesma posição social, o que não se verifica nas relações de gênero no âmbito doméstico e familiar, onde a mulher ocupa um lugar histórico de vulnerabilidade e subjugação.

Esta forma de atuação estatal, além de revitimizar a mulher, tem como efeito simbólico a legitimação da desigualdade de gênero, invisibilizando a violência contra a mulher e contribuindo para a inefetividade da Lei Maria da Penha e seu sistema protetivo.

Romper com a violência simbólica dentro das estruturas do Poder Judiciário é um desafio para o Estado, que só poderá ser alcançado através da qualificação técnica de seus agentes, sistemática e continuada.

Somente com a mudança das percepções sociais, sobretudo dos magistrados acerca das problemáticas de gênero, a Lei Maria da Penha poderá ser aplicada como um novo paradigma no enfrentamento de todas as formas de violência contra a mulher, contribuindo para a construção de uma sociedade em que mulheres e homens possam estabelecer relações de respeito $\mathrm{e}$ igualdade.

\section{REFERÊNCIAS}

AGUIAR, Cristina et al. Guia de serviços de atenção a pessoas em situação de violência. Salvador: Fórum Comunitário de Combate a Violência/Grupo de Trabalho Rede de Atenção, 2002.

ARENDT, Hannah. Sobre a violência. Tradução André de Macedo Duarte. Rio de Janeiro: Civilização Brasileira, 2009. 
BARATTA, Alessandro. O paradigma do gênero: da questão criminal à questão humana. In: CAMPOS, Carmen Hein de (Org.). Criminologia e feminismo. Porto Alegre: Sulina, 1999.

BOURDIEU, Pierre. A dominação Masculina. 3. ed. Rio de Janeiro: Bertrand Brasil, 2003. . O Poder Simbólico. 5. ed. Rio de Janeiro: Bertrand Brasil, 2002.

BRASIL. Lei $n^{o}$ 11.340. 7 de agosto de 2006. Disponível em: $<$ http://www.planalto.gov.br/ccivil_03/_ato2004-2006/2006/lei/111340.htm>. Acesso em: 02 dez. 2015.

DIAS, Maria Berenice. A Lei Maria da Penha na justiça: a efetividade da Lei 11.340/06 de combate à violência doméstica e familiar contra a mulher. São Paulo: Revista dos Tribunais, 2008.

FGV DIREITO SP. A violência doméstica fatal: o problema do feminicídio íntimo no Brasil. Disponível em: <www.pnud.org.br/arquivos/publicacao_feminicidio.pdf> Acesso em: 02 dez. 2015.

IPEA. Instituto de Pesquisa Econômica Aplicada. Sistema de Indicadores de Percepção Social (SIPS): tolerância social à violência contra as mulheres. Disponível em: $<$ www.ipea.gov.br/portal/images/stories/PDFs/SIPS/140327_sips_violencia_mulheres_novo.pdf $>$. Acesso em: 02 dez. 2015.

IPEA. Instituto de Pesquisa Econômica Aplicada. Violência contra a mulher: feminicídios no Brasil. Disponível em: <www.ipea.gov.br/.../130925_sum_estudo_feminicidio_leilagarcia.pdf > Acesso em: 02 dez. 2015.

MACHADO, Isadora Vier. Da dor no corpo à dor na alma: uma leitura do conceito de violência psicológica da Lei Maria da Penha. 2013. 282 f. Tese (Doutorado em Ciências Humanas)-Programa de Pós-Graduação Interdisciplinar em Ciências Humanas, Universidade Federal de Santa Catarina, Florianópolis.

MANSO, Almudena G.; SAUAIA, Artenira da Silva e Silva. Una aproximación exploratoria a la violencia contra la mujer en el Estado de Maranhão (Brasil): ¿debe cambiar la Ley Maria da Penha? Methaodos: revista de ciencias sociales, v. 3, n. 2, p. 207-220, 2015. Disponível em: $<$ http://dx.doi.org/10.17502/m.rcs.v3i2.86>. Acesso em: 30 dez. 2016.

; SAUAIA, Artenira da Silva e Silva. Violencia contra la mujer como mal endémico en la $\overline{\text { sociedad contemporânea. }}$

MEYER, Dagmar Estermann. Gênero e educação: teoria e política. In: LOURO, Guacira Lopes; NECKEL, Jane Felipe; GOELLNER, Silvana Vildore (Orgs.). Corpo, gênero e sexualidade: um debate contemporâneo na educação. 2. ed. Petrópolis, RJ: Vozes, 2005.

ORGANIZAÇÃO DAS NAÇÕES UNIDAS. Conferência de Direitos Humanos. Viena, junho de 1993. Disponível em: <http://www.dhnet.org.br/direitos/anthist/viena/viena.html>. Acesso em: 02 dez. 2015.

ORGANIZAÇÃO DOS ESTADOS AMERICANOS. Comissão Interamericana de Direitos Humanos. Convenção Interamericana para prevenir, punir e erradicar a violência contra a mulher: "Convenção de Belém do Pará”. 9 de junho de 1994. Disponível em: 
$<$ http://www.cidh.org/Basicos/Portugues/m.Belem.do.Para.htm>. Acesso em: 02 de dezembro de 2015.

SAFFIOTI Heleieth I. B.; ALMEIDA, Suely S. de. Violência de gênero: poder e impotência. Rio de Janeiro: REVINTER, 1995.

SAFFIOTI, Heleieth I. B. Contribuições feministas para o estudo da violência de gênero. Cadernos pagu, v. 16, p. 115-136, 2001.

. O poder do macho. Coleção polêmica. São Paulo: Moderna, 1987.

. Violência doméstica: questão de polícia e da sociedade. Campinas: Gênero e Cidadania PAGU/Núcleo de Estudos de Gênero - UNICAMP, 2004.

SCOTT, Joan W. Gênero: uma categoria útil de análise histórica. Educação e Realidade, v. 16, n. 2, Porto Alegre, jul./dez. 1990.

Recebido em: 02/09/2016

Aceito em: 11/11/2016 
